\title{
Describing Variability in Wing Shapes among Three Populations of Plesispareichei Using Landmark-Based Geometric Morphometric Analysis
}

\author{
Mark Ronald S. Manseguiao, Jessie G. Gorospe, Sharon Rose M. Tabugo, Muhmin Michael E. \\ Manting, Mark Anthony J. Torres, and Cesar G. Demayo
}

\begin{abstract}
This study was conducted to describe variability in 3 populations of a coconut pest, Plesispareichei landmark-based geometric morphometric analysis of inner wing shapes. A total of 21 landmarks were used to represent dimensions in the left and right wings. Analysis of Variance, coordinate mapping, relative warp, Euclidean Distance Matrix and Cluster Analyses were used to analyze these landmarks. Results showed that significant variations were observed among populations. Variation in the left wing is mainly seen along the proximal landmark points but is variable in the right wing which may be an indication of asymmetry. Cluster analysis showed wing shape variations between populations indicating population differentiation in the pest. Distance was not a factor which may indicate differences in genetic structure between populations.
\end{abstract}

Index Terms-Asymmetry, coconut beetle, landmarks, warp.

\section{INTRODUCTION}

An emerging pest in Malaysia, Plesispareichei (Chapui) is considered as a potential pest of the coconut tree in Philippines [1]. The species is morphologically similar to Brontispalongissima (Gestro) [1], [2]. Outbreaks of $B$. longissima have been prevalent in the Philippines since it was detected in 2005 however due to similarity in appearance, outbreaks of $P$. reichei might have been misreported. Continuous high warmtropical weather and low natural enemy populations may have contributed as factors for outbreaks in many geographical areas where coconuts are planted in abundance [3]. The success of this winged insect to infest on coconuts leading to outbreaks can be attributed to the pest ability to transfer from plant to plant and from one area to another. It was therefore the objective of this study to describe population diversity by looking into variations in wing shapes which are known to be affected by environmental factors thereby affecting its feeding distribution by increasing reproductive success in an area [4].

Insect wings evolve rapidly and its development is thought to be controlled by one or a set of genes [5]-[7] and can be

Manuscript received March 4, 2014; revised May 10, 2014. This work was supported by the Philippine Department of Science and Technology under the Accelerated Science and Technology Human Resource Development Program.

M. R. S. Manseguiao, S. R. M. Tabugo, M. M. E. Manting, M. A. J. Torres, and C. G. Demayo are with the Department of Biological Sciences in Mindanao State University - Iligan Institute Technology, Iligan, Philippines (e-mail: mark.manseguiao@gmail.com, sharonrose0297@gmail.com; muhminmichael, manting@gmail.com and torres, markanthony@gmail.com, cgdemayo@gmail.com).

J. M. Gorospe is with the School of Graduate Studies at the Naawan campus of the Mindanao State University system, Philippines. used to measure variation of a species across a geographic landscape [8]. We apply landmark-based geometric morphometric methods to measure the phenotypic variation in the wings [9]. Shape or reference points are reduced to a set of coordinates where statistical analyses are employed to permit comparison of shape similarities [10]. Changes in the shape and size of a structure in an organism may offer a better understanding to its development and evolution thus it is a useful tool to measure the phenotypic changes by which an organism adapts to a new environment [11]. Thus, understanding shape variations in the wings will allow a better understanding of diversity in pest populations which may contribute to the development of a better management of this pest.

\section{MATERIAL AND METHODS}

\section{A. Collection and Identification}

Adult coconut leaf beetles, $P$. reichei, were randomly collected from coconuts from three different locations in Mindanao Island, Philippines (Fig. 1). Pure ethyl alcohol was used as a preservative during transport. Identification of specimens was done according to Staines [12]. Individuals were then labeled by location and stored individually in Eppendorf tubes with 3-5 drops of pure ethyl alcohol.

\section{B. Imaging and Landmarking of Specimens}

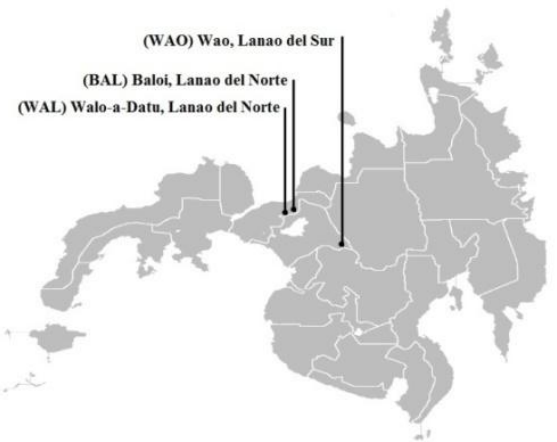

Fig. 1. Map of sampling sites in Mindanao Island, Philippines.

Images of the wings of the specimens was done by using a digital camera enhanced through a stereomicroscope. A total of 21 landmarkpoints were chosen (Fig. 2, Table I). These landmark points were chosen to represent major dimensions of the wings. These landmark points were established on the digitized images using tpsDig software v2.12 [13]. The landmark points are superimposed onto the image that generates two-dimensional coordinates. General Least 
Squares (GLS) Procrustes superimposition method was done to standardize the coordinates and to remove variation due to differences in translation, orientation and size [14], [15].

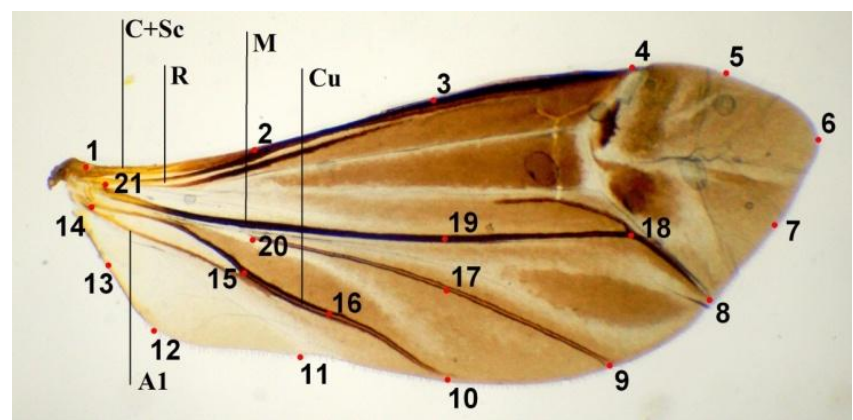

Fig. 2. P. reichei (Chapui) wing showing veins used as indicators of the landmark points. Legend: $C=$ Costa, $S c=$ Subcosta, $R=$ Radius, $M=$ Media, $A=$ Anal.

TABLE I: DESCRIPTIONS OF ANATOMICAL LANDMARK POINTS ON THE WING OF PLESISPA REICHEI (CHAPUI)

\begin{tabular}{|c|c|c|c|}
\hline $\begin{array}{l}\text { Landmark } \\
\text { no. (LM) }\end{array}$ & Description & $\begin{array}{l}\text { Landmark } \\
\text { no. (LM) }\end{array}$ & Description \\
\hline 1 & $\begin{array}{l}\text { Proximal end of } \\
\mathrm{C}+\mathrm{Sc}\end{array}$ & 12 & $\begin{array}{l}\text { Distal end of proximal } \\
\text { lateral margin }\end{array}$ \\
\hline 2 & Distal end of $\mathrm{C}+\mathrm{Sc}$ & 13 & $\begin{array}{l}\text { Midpoint of proximal } \\
\text { lateral margin }\end{array}$ \\
\hline 3 & $\begin{array}{l}\text { Midpoint of LM } 2 \\
\text { and4 }\end{array}$ & 14 & Proximal end of A1 \\
\hline 4 & Distal end of $\mathrm{R}$ & 15 & Distal end of A1 \\
\hline 5 & $\begin{array}{l}\text { Midpoint of LM4 and } \\
6\end{array}$ & 16 & $\begin{array}{l}\text { Midpoint of LM10 } \\
\text { and } 15\end{array}$ \\
\hline 6 & Distal point of wing & 17 & $\begin{array}{l}\text { Midpoint of LM } 9 \text { and } \\
20\end{array}$ \\
\hline 7 & $\begin{array}{l}\text { Midpoint of LM } 6 \\
\text { and } 8\end{array}$ & 18 & Curve of M \\
\hline 8 & Distal end $\mathrm{M}$ & 19 & $\begin{array}{l}\text { Midpoint of LM } 18 \\
\text { and } 20 \text { on M }\end{array}$ \\
\hline 9 & $\begin{array}{l}\text { Distal end of wing } \\
\text { fold }\end{array}$ & 20 & $\begin{array}{l}\text { Proximal end of wing } \\
\text { fold }\end{array}$ \\
\hline 10 & Distal end of $\mathrm{Cu}$ & 21 & Proximal end of $\mathrm{M}$ \\
\hline 11 & $\begin{array}{l}\text { Midpoint of } 10 \text { and } \\
12\end{array}$ & & \\
\hline
\end{tabular}

\section{Image Analysis}

Relative warp analysis using tpsRelW [16], following the algorithms developed by Bookstein [14] were used to describe variations in the wings within the populations based from a consensus or mean shape. Thin plate splines were then used to visualize the transformation of the wing by using the same software. Box plots were also generated to show the distribution of the populations away from the mean shape using PAST software 1.91 [17].

Euclidean Distance Matrix Analysis (EDMA) was done using PAST software 1.91 [17]. EDMA is a coordinate free approach in determining the correspondence between landmark points to further evaluates the changes between landmark points [18]. Principal Component Analysis (PCA) inherent in the EDMA method reduces data to determine which components retain the highest degree of the variation in the point to point analysis [19].

\section{Statistical Analysis}

The mean differences in wing centroid size among populations were determined and subjected to Analysis of Variance (ANOVA) and Tukey's test to show significant interactions between the populations using PaST software 1.91 [17]. A heatmap was also generated by using the same program to illustrate points of contraction and expansion.
Cluster Analysis was used to compare similarities among populations based on centroid size.

\section{RESULTS AND DISCUSSION}

ANOVA results showed significant differences across the three populations of in the right wing $P$. reichei (Table II-Table III). Significant differences were also found in the left wing except between BAL and WAO populations (Table IV-Table V).

TABLE II: RESULTS OF ANOVA TEST FOR SIGNIFICANT VARIATION IN THE CENTROID SIZES OF THE RIGHT WING OF $P$. REICHEI

\begin{tabular}{llllll}
\hline \hline & $\begin{array}{l}\text { Sum of } \\
\text { squares }\end{array}$ & Df & $\begin{array}{l}\text { Mean } \\
\text { Squares }\end{array}$ & F & P(same) \\
\hline $\begin{array}{l}\text { Between } \\
\text { groups }\end{array}$ & $1.18 \times 10^{06}$ & 2 & 589425 & 14.99 & $1.36 \times 10^{-06}$ \\
Within groups & $5.19 \times 10^{06}$ & 132 & 39324.4 & & \\
Total & $6.37 \times 10^{06}$ & 134 & & & \\
\hline \hline
\end{tabular}

TABLE III: TUKEY'S PAIRWISE COMPARISONS OF THE RIGHT WING

\begin{tabular}{cccc}
\multicolumn{4}{c}{ BETWEEN THREE POPULATIONS OF P. REICHEI } \\
\hline BAL & BAL & WAL & WAO \\
WAL & 7.73 & $\underline{2.18 \times 10^{-05}}$ & $\underline{0.01}$ \\
WAO & 4.29 & 3.44 & $\underline{0.04}$ \\
\hline
\end{tabular}

TABLE IV: RESULTS OF ANOVA TEST FOR SIGNIFICANT VARIATION IN THE CENTROID Sizes of THE LEFT Wing BETWEen THREE PopUlations of $P$.

\begin{tabular}{llclll}
\multicolumn{5}{c}{ REICHEI } \\
\hline \hline $\begin{array}{l}\text { Sum of } \\
\text { squares }\end{array}$ & Df & $\begin{array}{l}\text { Mean } \\
\text { Squares }\end{array}$ & F & P(same) \\
\hline $\begin{array}{l}\text { Between } \\
\text { groups }\end{array}$ & $1.02 \times 10^{06}$ & 2 & 509379 & 16.36 & $4.51 \times 10^{-07}$ \\
$\begin{array}{l}\text { Within groups } \\
\text { Total }\end{array}$ & $\begin{array}{l}4.11 \times 10^{06} \\
5.13 \times 10^{06}\end{array}$ & 132 & 31141.7 & & \\
\hline \hline
\end{tabular}

TABLE V: TUKEY'S PAIRWISE COMPARISONS OF THE LEFT WING BETWEEN THREE POPULATIONS OF P. REICHEI

\begin{tabular}{llll}
\hline \hline & BAL & WAL & WAO \\
\hline BAL & & $\underline{0}$ & 0.07 \\
WAL & 4.94 & & $\underline{2.18 \times 10^{-05}}$ \\
WAO & 3.08 & 8.02 & \\
\hline \hline
\end{tabular}

Relative warp analysis which compares wing morphology across the three populations shows three relative warps that were significant in both the left and right wings (Table VI and Table VII, Fig. 3 and Fig. 4). Variation between populations are also graphically shown in the inset box plots.

TABLE VI: VARIATION IN THE RIGHT WING BETWEEN THREE POPULATIONS OF P. REICHEI EXPLAINED BY THE SIGNIFICANT RELATIVE WARPS AND THE CORRESPONDING PERCENTAGE VARIANCE

\begin{tabular}{ccl}
\hline $\begin{array}{c}\text { Relative } \\
\text { Warp }\end{array}$ & $\begin{array}{c}\% \\
\text { Variance }\end{array}$ & \multicolumn{1}{c}{ Description } \\
\hline \hline 1 & 53.06 & $\begin{array}{l}\text { Variation along the lower and proximal margins } \\
\text { of the wing }\end{array}$ \\
\hline 2 & 18.43 & Variation along the distal margins of the wing \\
\hline 3 & 11.38 & Variation along the upper margins of the wing \\
\hline \hline
\end{tabular}

TABLE VII: VARIATION IN THE LEFT WING BETWEEN THREE POPULATIONS OF P. REICHEI EXPLAINED BY THE SIGNIFICANT RELATIVE WARPS AND THE

\begin{tabular}{ccc}
\multicolumn{3}{c}{ CORRESPONDING PERCENTAGE VARIANCE } \\
\hline \hline $\begin{array}{c}\text { Relative } \\
\text { Warp }\end{array}$ & $\begin{array}{c}\% \\
\text { Variance }\end{array}$ & Description \\
\hline \hline 1 & 57.49 & Variation along the lower margins of the wing \\
\hline 2 & 17.22 & Variation along the distal margins of the wing \\
\hline 3 & 6.88 & Variation along the upper margins of the wing \\
\hline \hline
\end{tabular}




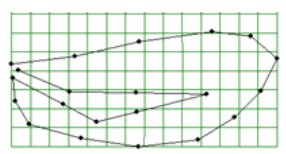

$\mathbf{R W 1}=\mathbf{5 7 . 4 9}$
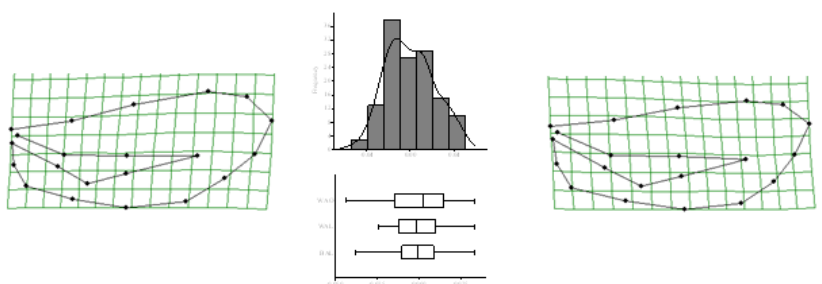

$\mathrm{RW2}=\mathbf{1 7 . 2 2}$
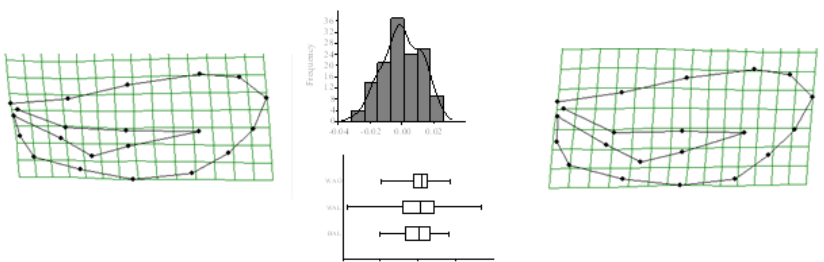

$\mathrm{RW3}=6.88$
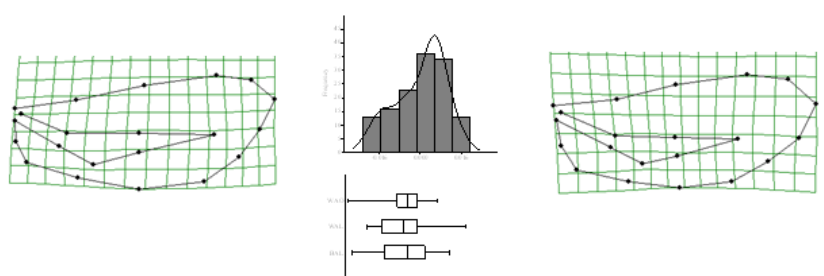

Fig. 3. Summary of the geometric morphometric relative warp analysis of the left wing showing the consensus morphology (uppermost panel) and the variation in the shapes of the pronotum among the three populations of $P$. reichei.

The first relative warp of the left wing ( $\mathrm{RW} 1=57.49)$ shows a variation along the lower and distal margin of the wing with a bimodal distribution by which a portion of all three populations contributes to a positively oriented lesser peak. The same is observed in the second relative warp (RW2=17.22). The last significant warp (RW3=6.88) shows also a bimodal distribution but the lesser peak is negatively oriented.

The right wing relative warp analysis shows that most of the population $(\mathrm{RW} 1=53.06)$ is explained by a variation along the lower margin of the wing with a bimodal distribution with the lesser peak negatively oriented contributed mainly by WAO. The second relative warp $(\mathrm{RW}=18.43)$ has a trimodal distribution with the two lesser peaks oriented positively. The third significant relative warp shows a bimodal distribution with the lesser peak oriented negatively.

Coordinate maps of the landmark points in the insect wings were generated to visualize the coordinates across the populations to compare points of variation in the landmarks with a corresponding heatmap of expansion and contraction landmark points (Fig. 4 and Fig. 5). Contraction and expansion points in the right wing are seen on the proximal and distal ends of the wings whereas the left wing has a relatively neutral margin with the exception of contraction points in the distal ends. Euclidean Distance Matrix Analysis (EDMA) and Principal Component Analysis (PCA) further evaluate the distances between two landmark points to determine the landmark points that contribute to the changes in wing morphology.

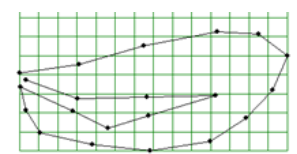

$\mathrm{RW1}=\mathbf{5 3 . 0 6}$
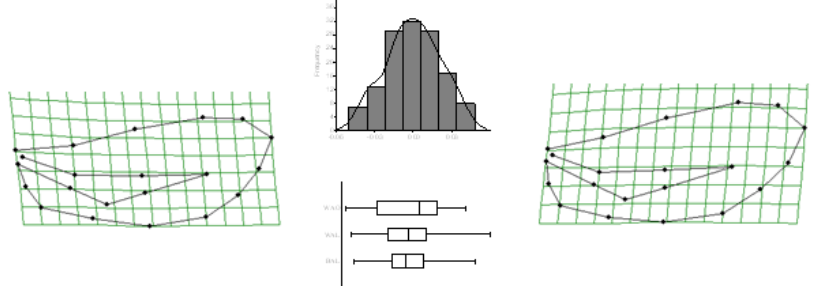

RW2 $=18.43$
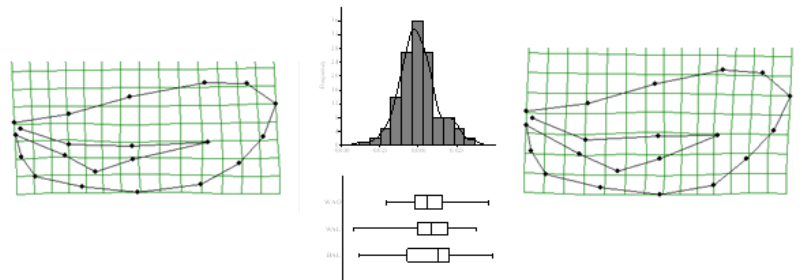

RW3 $=11.38$
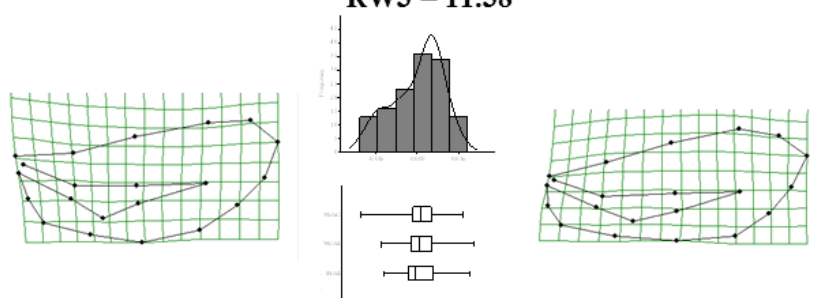

Fig. 4. Summary of the geometric morphometric relative warp analysis of the right wing showing the consensus morphology (uppermost panel) and the variation in the shapes of the pronotum among the three populations of $P$. reichei.
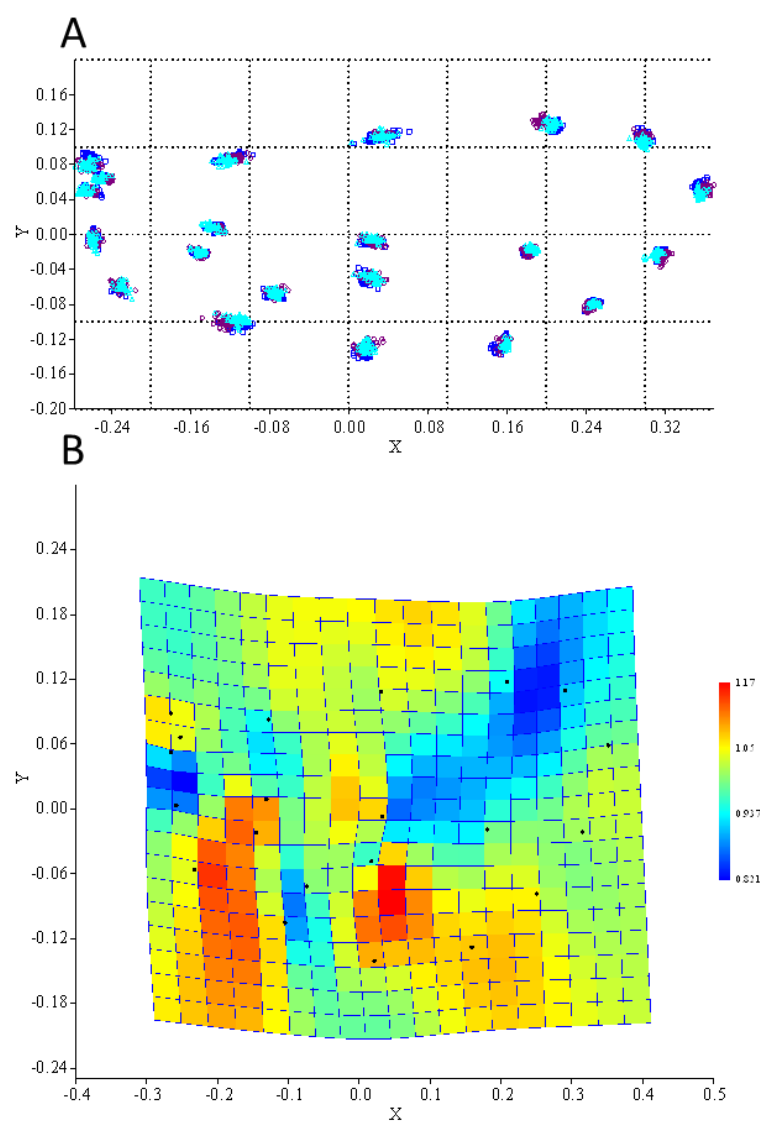

Fig. 5. Plot of landmark points of the right wing of $P$. reichei across populations (A) and (B) points of expansion (blue) and contraction (red) in the wing across three populations. 
A

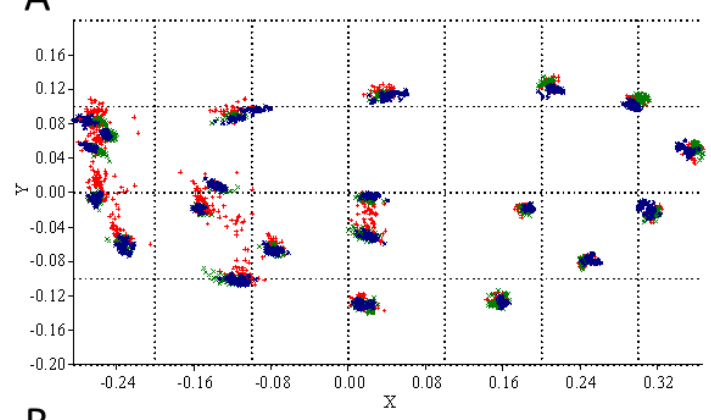

B

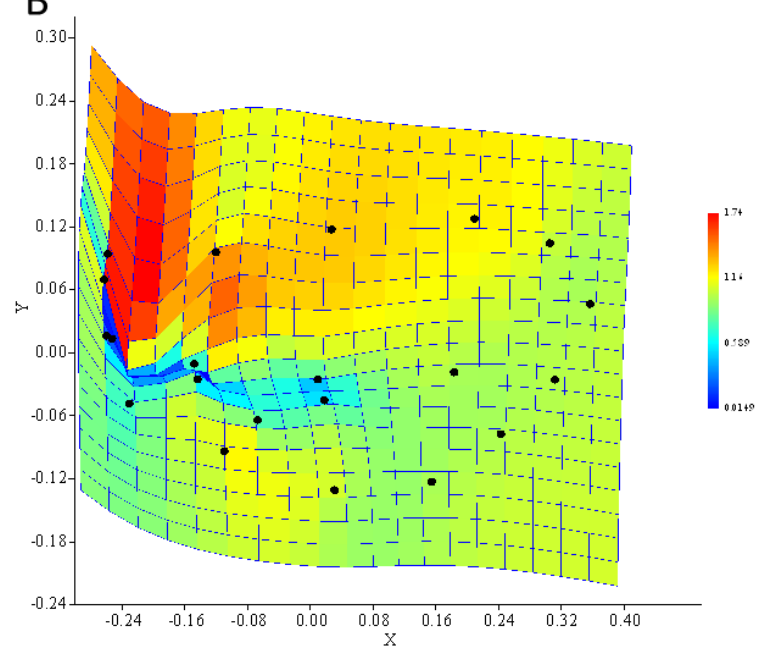

Fig. 6. Plot of landmark points of the left wing of $P$. reichei across populations (A) and (B) points of expansion (blue) and contraction (red) in the wing across three populations.

TABLE VIII: INTER-LANDMARK (LM) DISTANCES WITH THE TOP 10\% PCA SCORES FOR THE SIGNIFICANT COMPONENTS OF THE PROCRUSTES

TRANSFORMED LANDMARK COORDINATES OF THE LEFT WING OF PLESISPA REICHEI (CHAPUI) FROM THREE LOCATIONS IN MINDANAO

\begin{tabular}{cccccccc}
\hline \hline \multicolumn{2}{c}{ PC1 } & \multicolumn{2}{c}{ PC2 } & \multicolumn{2}{c}{ PC3 } & \multicolumn{2}{c}{ PC4 } \\
\%var=37.39\% & \%var=20.26\% & \%var=10.50 & & \\
\hline LM & Value & LM & Value & LM & value & LM & value \\
\hline $12-21$ & 0.3105 & $2-21$ & 0.1849 & $13-21$ & 0.1823 & $3-20$ & 0.2291 \\
$11-21$ & 0.2634 & $1-2$ & 0.1762 & $11-19$ & 0.1657 & $3-21$ & 0.1884 \\
$10-21$ & 0.2205 & $1-21$ & 0.1667 & $12-20$ & 0.1628 & $2-21$ & 0.182 \\
$11-20$ & 0.2196 & $2-14$ & 0.1473 & $5-11$ & 0.1579 & $3-12$ & 0.1485 \\
$10-20$ & 0.2018 & $1-3$ & 0.1461 & $12-21$ & 0.1547 & $5-20$ & 0.1436 \\
$16-21$ & 0.1995 & $1-20$ & 0.1398 & $11-18$ & 0.1469 & $3-15$ & 0.1397 \\
$16-20$ & 0.1882 & $2-20$ & 0.1308 & $8-11$ & 0.1459 & $2-12$ & 0.134 \\
$9-21$ & 0.1847 & $3-21$ & 0.1284 & $6-11$ & 0.1451 & $6-20$ & 0.1326 \\
$9-20$ & 0.1735 & $1-11$ & 0.1189 & $4-11$ & 0.143 & $3-11$ & 0.1264 \\
$15-21$ & 0.158 & $11-14$ & 0.1188 & $2-13$ & 0.1364 & $3-16$ & 0.1216 \\
$17-21$ & 0.1434 & $3-14$ & 0.1173 & $13-20$ & 0.1352 & $5-19$ & 0.119 \\
$8-21$ & 0.1296 & $2-13$ & 0.1172 & $7-11$ & 0.1351 & $3-13$ & 0.1183 \\
$17-20$ & 0.1292 & $1-19$ & 0.1168 & $9-11$ & 0.1341 & $2-20$ & 0.1163 \\
$8-20$ & 0.1288 & $14-20$ & 0.1165 & $3-11$ & 0.1289 & $2-13$ & 0.1159 \\
$13-21$ & 0.1225 & $1-17$ & 0.1103 & $17-19$ & 0.1148 & $4-20$ & 0.1094 \\
$19-21$ & 0.1104 & $1-4$ & 0.1095 & $2-12$ & 0.1145 & $6-19$ & 0.1084 \\
$18-20$ & 0.1049 & $1-9$ & 0.1044 & $10-19$ & 0.1131 & $5-17$ & 0.1041 \\
$18-21$ & 0.1034 & $3-20$ & 0.1038 & $1-2$ & 0.1041 & $3-19$ & 0.1036 \\
$19-20$ & 0.1031 & $14-21$ & 0.1028 & $11-17$ & 0.1014 & $2-14$ & 0.1031 \\
$2-14$ & 0.0711 & $2-12$ & 0.1018 & $3-13$ & 0.0958 & $3-14$ & 0.1011 \\
$7-20$ & 0.0666 & $1-8$ & 0.099 & $2-14$ & 0.0952 & $6-17$ & 0.1008 \\
\hline \hline
\end{tabular}

EDMA and PCA assessed the 210 possible inter-landmark measurement combinations from the 21 landmarks in the wings. Four component axes were found to be significant in explaining the variation of the left wing. The top $10 \%$ of expanding inter-landmark points were found to be between landmark points in the lower part of the wings (Table VIII) and the proximal point of the median vein (LM21) or the proximal landmark of the wing fold (LM20), with
LM12-LM21 having the highest expansion, indicating an increase in the lower margins of the wing. The bottom $10 \%$ of contraction inter-landmark points was observed to be between upper margins landmarks and between the proximal and distal points in the wings (Table X), with LM1-LM21 waving the most contraction. These observations indicate that the wing become shorter from proximal to distal point but longer in the upper margin to the lower margin.

TABLE IX: INTERLANDMARK (INTER-LM) DISTANCES WITH THE TOP 10\% PCA SCORES FOR THE SIGNIFICANT COMPONENTS OF THE PROCRUSTES TRANSFORMED LANDMARK COORDINATES OF THE RIGHT WING OF

\begin{tabular}{cccccccccc}
\multicolumn{8}{c}{ P. REICHEI FROM THRE LOCATIONS IN MINDANAO } \\
\hline \hline \multicolumn{3}{c}{ PC1 } & \multicolumn{2}{c}{ PC2 } & \multicolumn{2}{c}{ PC3 } & \multicolumn{2}{c}{ PC4 } & \multicolumn{2}{c}{ PC5 } \\
\%var=24.22\% & \%var=15.75\% & \%var=12.33 & \%var=6.39 & \multicolumn{2}{c}{ \%var=5.25 } \\
\hline LM & value & LM & value & LM & value & LM & value & LM & value \\
\hline $6-11$ & 0.1975 & $3-20$ & 0.2061 & $3-4$ & 0.1912 & $1-11$ & 0.2309 & $1-16$ & 0.1574 \\
$7-11$ & 0.1869 & $3-13$ & 0.1845 & $2-4$ & 0.1821 & $11-12$ & 0.194 & $7-19$ & 0.1502 \\
$5-11$ & 0.1736 & $3-21$ & 0.1804 & $7-10$ & 0.1332 & $11-13$ & 0.1844 & $7-17$ & 0.1448 \\
$3-11$ & 0.1322 & $3-15$ & 0.1738 & $7-17$ & 0.1293 & $11-21$ & 0.164 & $1-20$ & 0.142 \\
$4-7$ & 0.1201 & $3-12$ & 0.1669 & $4-10$ & 0.1289 & $11-15$ & 0.154 & $1-10$ & 0.1417 \\
$6-10$ & 0.1196 & $3-14$ & 0.164 & $8-17$ & 0.1182 & $11-14$ & 0.1407 & $1-7$ & 0.141 \\
$4-6$ & 0.1194 & $1-3$ & 0.1455 & $8-10$ & 0.1176 & $2-11$ & 0.1334 & $1-15$ & 0.1361 \\
$5-9$ & 0.1112 & $2-13$ & 0.1376 & $4-16$ & 0.1152 & $1-10$ & 0.1312 & $13-16$ & 0.1105 \\
$5-10$ & 0.1096 & $2-21$ & 0.1361 & $4-17$ & 0.1127 & $1-12$ & 0.1284 & $9-17$ & 0.1098 \\
$6-17$ & 0.1083 & $3-16$ & 0.1305 & $10-19$ & 0.1089 & $12-17$ & 0.1154 & $1-11$ & 0.1061 \\
$6-9$ & 0.1081 & $2-14$ & 0.1206 & $7-9$ & 0.1087 & $1-17$ & 0.1119 & $1-2$ & 0.1025 \\
$7-10$ & 0.1037 & $4-20$ & 0.1156 & $2-7$ & 0.1081 & $2-12$ & 0.1074 & $14-16$ & 0.1015 \\
$11-18$ & 0.1025 & $2-12$ & 0.115 & $6-10$ & 0.1059 & $10-15$ & 0.1063 & $12-16$ & 0.1014 \\
$6-16$ & 0.1023 & $4-19$ & 0.1132 & $10-18$ & 0.1037 & $15-17$ & 0.1055 & $6-19$ & 0.101 \\
$4-11$ & 0.0997 & $11-13$ & 0.1035 & $2-8$ & 0.09844 & $6-18$ & 0.1054 & $10-13$ & 0.09436 \\
$5-18$ & 0.09928 & $4-17$ & 0.102 & $3-5$ & 0.09765 & $5-18$ & 0.1049 & $7-14$ & 0.09183 \\
$6-18$ & 0.09823 & $1-2$ & 0.09781 & $8-9$ & 0.09633 & $11-20$ & 0.1033 & $14-20$ & 0.09132 \\
$9-11$ & 0.09699 & $11-12$ & 0.09292 & $5-10$ & 0.09575 & $2-10$ & 0.1012 & $13-15$ & 0.08559 \\
$8-11$ & 0.09648 & $11-21$ & 0.09282 & $6-17$ & 0.09188 & $10-12$ & 0.1001 & $12-20$ & 0.08396 \\
$7-17$ & 0.09464 & $4-15$ & 0.0866 & $2-5$ & 0.09128 & $12-19$ & 0.0989 & $1-21$ & 0.08387 \\
$5-17$ & 0.09375 & $3-11$ & 0.08533 & $7-19$ & 0.09094 & $16-17$ & 0.09195 & $10-14$ & 0.08362 \\
\hline \hline
\end{tabular}

TABLE X: INTERLANDMARK (INTER-LM) DISTANCES WITH THE BOTTOM $10 \%$ PCA SCORES FOR THE SIGNIFICANT COMPONENTS OF THE PROCRUSTES TRANSFORMED LANDMARK COORDINATES OF THE LEFT WING OF P. REICHEI FROM THREE LOCATIONS IN MINDANAO

\begin{tabular}{cccccccc}
\hline \hline \multicolumn{2}{c}{ PC1 } & \multicolumn{2}{c}{ PC2 } & \multicolumn{2}{c}{ PC3 } & \multicolumn{2}{c}{ PC4 } \\
\%var=37.39\% & \multicolumn{2}{c}{ \%var=20.26\% } & \multicolumn{2}{c}{ \%var=10.50 } & \multicolumn{2}{c}{ \%var=5.42 } \\
\hline LM & value & LM & value & LM & value & LM & value \\
\hline $3-5$ & -0.0436 & $7-19$ & -0.0803 & $9-20$ & -0.09452 & $2-5$ & -0.08838 \\
$6-12$ & -0.04885 & $6-20$ & -0.08442 & $3-20$ & -0.09572 & $14-20$ & -0.08918 \\
$4-6$ & -0.05065 & $10-11$ & -0.08649 & $10-20$ & -0.09655 & $1-18$ & -0.09027 \\
$7-12$ & -0.05072 & $5-18$ & -0.08685 & $4-21$ & -0.09743 & $14-17$ & -0.09039 \\
$2-21$ & -0.05222 & $6-18$ & -0.08819 & $2-7$ & -0.09952 & $1-20$ & -0.0919 \\
$6-19$ & -0.05267 & $5-19$ & -0.09237 & $7-21$ & -0.1028 & $3-8$ & -0.09504 \\
$3-7$ & -0.05606 & $5-17$ & -0.09479 & $6-21$ & -0.108 & $12-20$ & -0.09931 \\
$5-19$ & -0.05697 & $6-17$ & -0.1007 & $5-20$ & -0.1113 & $1-8$ & -0.1014 \\
$3-6$ & -0.06029 & $6-19$ & -0.1031 & $19-21$ & -0.1127 & $2-7$ & -0.1023 \\
$2-5$ & -0.06294 & $4-5$ & -0.1031 & $8-20$ & -0.1133 & $2-9$ & -0.1023 \\
$2-19$ & -0.06519 & $7-11$ & -0.1147 & $11-14$ & -0.1137 & $13-20$ & -0.1038 \\
$3-19$ & -0.06538 & $4-7$ & -0.1215 & $18-20$ & -0.1191 & $2-17$ & -0.1058 \\
$15-20$ & -0.06762 & $3-7$ & -0.1234 & $4-20$ & -0.1202 & $1-19$ & -0.1073 \\
$2-7$ & -0.07251 & $4-6$ & -0.125 & $1-21$ & -0.1227 & $2-19$ & -0.111 \\
$2-6$ & -0.07721 & $3-5$ & -0.135 & $11-12$ & -0.1238 & $1-17$ & -0.1121 \\
$13-20$ & -0.124 & $5-11$ & -0.1407 & $2-19$ & -0.1269 & $15-20$ & -0.1142 \\
$14-20$ & -0.1576 & $2-7$ & -0.1455 & $17-20$ & -0.133 & $3-4$ & -0.1294 \\
$2-20$ & -0.176 & $3-6$ & -0.1461 & $11-13$ & -0.1334 & $2-4$ & -0.132 \\
$1-20$ & -0.1862 & $6-11$ & -0.1466 & $6-20$ & -0.1369 & $2-18$ & -0.1368 \\
$14-21$ & -0.1945 & $2-5$ & -0.1663 & $7-20$ & -0.1417 & $2-8$ & -0.1418 \\
$1-21$ & -0.305 & $2-6$ & -0.1746 & $19-20$ & -0.1508 & $13-21$ & -0.1496 \\
\hline \hline
\end{tabular}

A similar effect is also seen in the right wing. Expansion is seen between distances in the distal landmark points of the wing to the lower margin points (Table IX), with LM6-LM11 having the longest distance. Contraction is observed in the landmark points in the right wing between points in the lower margins of the wing to the proximal landmark points (Table XI), with LM11-LM14 having the shortest distance. 
Overall, the contraction and expansion of the landmark points suggest that the overall shape of the wings become shorter from proximal to distal landmark points and broader between points in the upper margins to the lower margins. Also, the proximal points become closer together suggesting a slender wing.

According to Chapman [20], narrower and petiolate bases are characteristics of slow-flying insects while those with broader bases are faster. Based on the data, the wings of P.reichei from the three populations are observed to be more narrow proximally, shorter in length and broader between the leading edge to the trailing edge of the wing. This suggests that wing shape contribute to a slower flight but more powerful since more force is produced to lift the body up.

TABLE XI: INTERLANDMARK (INTER-LM) DISTANCES WITH THE BOTTOM $10 \%$ PCA SCORES FOR THE SIGNIFICANT COMPONENTS OF THE PROCRUSTES

TRANSFORMED LANDMARK COORDINATES OF THE RIGHT WING OF $P$. REICHEI FROM THREE LOCATIONS IN MINDANAO

\begin{tabular}{cccccccccc}
\multicolumn{8}{c}{ REICHEI FROM THREE LOCATIONS IN MINDANAO } \\
\hline \hline \multicolumn{1}{c}{ PC1 } & \multicolumn{2}{c}{ PC2 } & \multicolumn{2}{c}{ PC3 } & \multicolumn{2}{c}{ PC4 } & \multicolumn{2}{c}{ PC5 } \\
\%var=24.22\% & \%var=15.75\% & \%var=12.33 & \%var=6.39 & \multicolumn{2}{c}{ \%var=5.25 } \\
\hline LM & value & LM & value & LM & value & LM & value & LM & value \\
\hline $14-19$ & -0.0949 & $3-18$ & -0.0955 & $4-5$ & -0.0987 & $4-21$ & -0.0737 & $5-16$ & -0.0874 \\
$1-10$ & -0.0950 & $1-19$ & -0.0960 & $3-12$ & -0.1001 & $2-3$ & -0.0746 & $5-20$ & -0.0895 \\
$9-21$ & -0.0957 & $2-18$ & -0.0960 & $17-21$ & -0.1005 & $8-19$ & -0.0841 & $10-18$ & -0.0903 \\
$18-21$ & -0.0967 & $8-11$ & -0.101 & $3-20$ & -0.1019 & $3-21$ & -0.0845 & $3-20$ & -0.0936 \\
$19-21$ & -0.0971 & $2-8$ & -0.102 & $2-13$ & -0.1047 & $11-16$ & -0.0861 & $8-10$ & -0.0948 \\
$16-21$ & -0.0975 & $3-4$ & -0.1026 & $4-7$ & -0.108 & $4-14$ & -0.0900 & $16-18$ & -0.1005 \\
$14-16$ & -0.0997 & $3-8$ & -0.1077 & $14-17$ & -0.109 & $8-14$ & -0.0911 & $3-17$ & -0.1006 \\
$10-21$ & -0.1006 & $2-5$ & -0.1083 & $11-17$ & -0.1116 & $2-18$ & -0.0934 & $4-10$ & -0.1007 \\
$11-13$ & -0.1006 & $7-11$ & -0.1084 & $15-17$ & -0.113 & $10-11$ & -0.0949 & $8-16 /$ & -0.1048 \\
$10-14$ & -0.1023 & $9-11$ & -0.1137 & $1-19$ & -0.1161 & $7-11$ & -0.0996 & $17-21$ & -0.1085 \\
$14-17$ & -0.1025 & $6-11$ & -0.1142 & $2-21$ & -0.1181 & $9-17$ & -0.1006 & $17-19$ & -0.1089 \\
$1-4$ & -0.1026 & $2-17$ & -0.1181 & $12-17$ & -0.1247 & $3-14$ & -0.1011 & $4-15$ & -0.1121 \\
$17-21$ & -0.103 & $10-11$ & -0.1195 & $1-17$ & -0.1252 & $18-21$ & -0.1091 & $4-20$ & -0.1161 \\
$8-14$ & -0.1065 & $2-7$ & -0.125 & $3-21$ & -0.1262 & $18-20$ & -0.1099 & $4-16$ & -0.1219 \\
$8-21$ & -0.1092 & $11-19$ & -0.1318 & $13-17$ & -0.1273 & $8-17$ & -0.1102 & $2-17$ & -0.1375 \\
$4-14$ & -0.1199 & $2-6$ & -0.141 & $2-14$ & -0.1282 & $18-19$ & -0.1214 & $19-20$ & -0.1545 \\
$4-21$ & -0.1263 & $2-19$ & -0.1429 & $3-13$ & -0.1287 & $17-18$ & -0.1263 & $16-17$ & -0.1577 \\
$11-21$ & -0.1278 & $3-5$ & -0.1494 & $3-14$ & -0.1368 & $14-18$ & -0.1318 & $15-19$ & -0.1588 \\
$1-11$ & -0.1323 & $3-7$ & -0.1507 & $4-6$ & -0.1379 & $9-11$ & -0.163 & $16-19$ & -0.1603 \\
$2-4$ & -0.1361 & $11-17$ & -0.1558 & $1-2$ & -0.156 & $8-11$ & -0.1636 & $15-17$ & -0.1699 \\
$11-14$ & -0.1416 & $3-6$ & -0.1779 & $1-3$ & -0.166 & $11-18$ & -0.1752 & $17-20$ & -0.1753 \\
\hline \hline
\end{tabular}

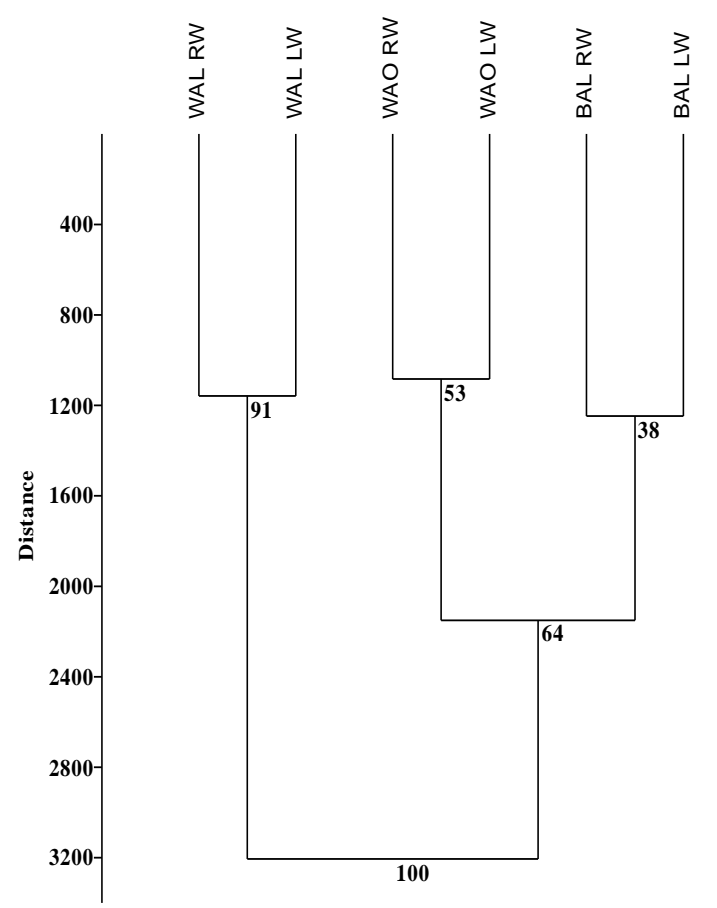

Fig. 7. Dendrogram of centroid size comparison using ward's method from three populations of $P$. reichei.
Cluster analysis of the centroid sizes of the wing morphology showed that the left and right wings were grouped according to geographic location. Each location is seen to be significantly different from each other $(p<0.5$; Fig. $7)$. Left and right wings were also significantly different except for BAL indicating functional asymmetry arises in the wings. Functional asymmetry is deviations in the bilateral symmetry of an organism believed to be induced by stresses in the environment. Furthermore, it shows that these environmental factors might be similar in BAL and WAO despite a large geographic distance between the two locations.

The variations observed in P.reichei may be attributed to the effects of latitude and altitude as has been observed in Drosophila melanogaster [21], [22]. Moreover these wing morphology changes including wing asymmetry may also be attributed to the diet during development [23], relative humidity and rainfall [24], [25].

\section{CONCLUSION}

This study has clearly described the variations in the wings of three geographically distant populations of $P$. reichei using landmark-based geometric morphometric analysis. While differences were observed between geographical locations, distance was not a factor for the differences which may indicate differences in the genetic structure of the populations. Environmental differences may also have triggered wing development. Similar environmental cues may produce similarity in wing landmarks but distinct geographically.

\section{ACKNOWLEDGEMENT}

Thanks are owed to the Philippine Department of Science and Technology under the Accelerated Science and Technology Human Resource Development Program for their prompt responses to queries regarding the study.

\section{REFERENCES}

[1] A. Sivapragasam and W. H. Loke, "Plesispareichei: A pest of increasing importance in Malaysia," in Proc. Developing an Asia-Pacific Strategy for Forest Invasive Species: the Coconut Beetle Problem-bridging Agriculture and Forestry. Asia-Pacific Forest Invasive Species Network Workshop, 2007, pp. 55-62, no. 2.

[2] R. J. Lever, Pests of the Coconut Palm, no. 18, Food \& Agriculture Org., 1969, pp. 112-113

[3] G. T. Choo-Toh, "An outbreak of Plesispareichei(Chapui) on palms in Singapore," in Proc. the 5th International Conference on Plant Protection in the Tropics, 1999, pp. 64-69.

[4] B. Cui and G. Liu, "Research significant of wing and vein among Insecta," International Journal of Biology, vol. 3, pp. 80-183, 2011.

[5] M. A. Sturtevant and E. Bier, "Analysis of the genetic hierarchy guiding wing vein development in Drosophila," Development 121, no. 3, pp. 785-801, 1995.

[6] S. F. Gilbert, J. M. Opitz, and R. A. Raff, "Resynthesizing evolutionary and developmental biology," Dev. Biol., vol. 173, pp. 357-372, 1996.

[7] M. A. J. Torres, L. A. Adamat, M. M. E. Manting, S. R. M. Tabugo, R. C. Joshi, L. Sebastian, A. T. Barrion, and C. G. Demayo, "Developmental modules defining the shapeof the forewing of Scotinopharacoarctata," Egypt. Acad. J. biolog. Sci., vol. 3, no. 1, pp. 105-112, 2010.

[8] T. M. Francoy, R. A. O. Silva, P. Nunes-Silva, C. Menezes, and V. L. Imperatriz-Fonseca, "Gender identification of five genera of stingless bees (Apidae, Meliponini) based on wing morphology," Genetics and molecular research, vol. 8, no. 1, pp. 207-214, 2009.

[9] F. J. Rohlf, Geometric Morphometrics and Phylogeny, Stony Brook, NY: State University of New York, 2002, pp. 175-193. 
[10] P. Mitteroecker and P. Gunz, "Advances in geometric morphometrics," Evolutionary Biology, vol. 36, no. 2, pp. 235-247, 2009.

[11] R. Laffont, C. Firmat, P. Alibert, B. David, S. Montuire, and T. Saucède, "Biodiversity and evolution in the light of morphometrics: From patterns to processes," ComptesRendusPalevol, vol. 10, no. 2, pp. 133-142, 2011.

[12] C. L. Staines. (2012). Hispines of the World. USDA/APHIS/PPQ. Center for Plant Health Science and Technology and National Natural History Museum. [Online]. Available: http://idtools.org/id/beetles/hispines

[13] F. J. Rohlf, TPSDig Version 2.12, Stony Brook, NY: State University of New York, 2008.

[14] F. L. Bookstein, Morphometric Tools for Landmark Data: Geometry and Biology, London, UK: Cambridge University Press, 1991.

[15] I. L. Dryden and K. V. Mardia, Statistical Analysis of Shape, Chichester, U.K: Wiley, 1998.

[16] F. J. Rohlf, TPSRelw Version 1.46, Stony Brook, NY: State University of New York, 2008.

[17] Ø. Hammer, D. A. T. Harper, and P. D. Ryan. (2001). Past: Paleontological statistics software package for education and data analysis. PaleontologíaElectrónica. [Online] 4. pp. 1-9. Available: http://palaeo-electronica.org/2001_1/past/issue1_01.html

[18] S. Lele and J. T. Richtsmeier, "Euclidean distance matrix analysis: confidence intervals for form and growth differences," American Journal of Physical Anthropology, vol. 98, no. 1, pp. 73-86, 1995.

[19] I. T. Jolliffe, "Principal component analysis," Springer Series in Statistics, vol. 29, 2002.

[20] R. F. Chapman, The Insects: Structure and Function, Cambridge, UK Cambridge University Press, pp. 193-225, 1998.

[21] W. Pitchers, J. E. Pool, and I. Dworkin, "Altitudinal clinal variation in wing size and shape in African Drosophila melanogaster: One cline or many?" Evolution, vol. 67, no. 2, pp. 438-452, 2013.

[22] H. Johnson, M. J. Solensky, D. A. Satterfield, and A. K. Davis, "Does skipping a meal matter to a butterfly's appearance? Effects of larval food stress on wing morphology and color in monarch butterflies," PloS one, vol. 9, no. 4, p. e93492, 2014.

[23] E. J. Márquez and C. I. Saldamando-Benjumea, "Rhodniusprolixus and Rhodniusrobustus-like (Hemiptera, Reduviidae) wing asymmetry under controlled conditions of population density and feeding frequency," Journal of biosciences, vol. 38, no. 3, pp. 549-560, 2013.

[24] G. F. Gómez, E. J. Márquez, L. A. Gutiérrez, J. E. Conn, and M. M. Correa, "Geometric morphometric analysis of Colombian Anopheles albimanus (Diptera: Culicidae) reveals significant effect of environmental factors on wing traits and presence of a metapopulation," Actatropica, vol. 135, pp. 75-85, 2014.

[25] M. J. D. Juri, J. Liria, J. C. Navarro, R. Rodriguez, and G. N. Fritz, "Morphometric variability of Anopheles pseudopunctipennis (Diptera: Culicidae) from different ecoregions of argentina and bolivia," Florida Entomologist, vol. 94, no. 3, pp. 428-438, 2011.

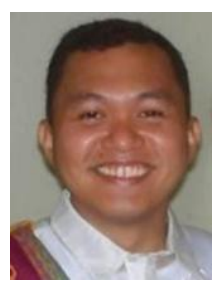

Mark Ronald S. Manseguiao is a graduate student taking up master's study in science in biology at the Mindanao State University of Science and Technology - Iligan Institute of Technology, Iligan City, Philippines under a scholarship grant with the Philippine Department of Science and Technology Accelerated Science and technology Human Resource Development Program. He took up his baccalaureate degree in biology at the University of the Philippines Mindanao, Davao City, Philippines.

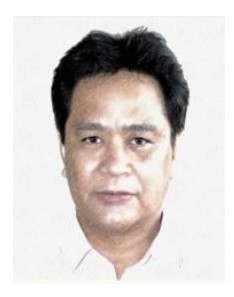

Jessie G. Gorospe is a faculty and the dean of the School of Graduate Studies at the Naawan Campus of the Mindanao State University system.

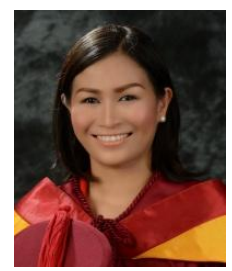

Sharon Rose M. Tabugo is an associate professor in the Department of Biological Sciences in Mindanao State University - Iligan Institute Technology.

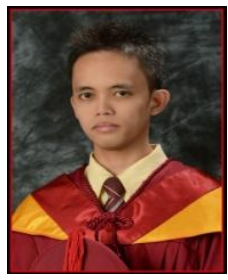

MuhminMichael E. Manting is an instructor in the Department of Biological Sciences in Mindanao State University - Iligan Institute Technology.

Mark Anthony J. Torres is an associate professor in the Department of Biological Sciences in Mindanao State University - Iligan Institute Technology. He is also a director at the Institute for Peace and Development in Mindanao of the University

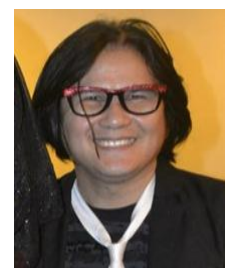

Cesar G. Demayo is the graduate adviser of the lead author and department chairman of the Department of Biological Sciences in Mindanao State University Iligan Institute Technology, Iligan, Philippines 9200. 